\title{
BMJ
}

\section{Differences in atherosclerosis according to area level socioeconomic deprivation: cross sectional, population based study}

\begin{abstract}
Kevin A Deans, specialist registrar, ${ }^{1}$ Vladimir Bezlyak, biostatistician, ${ }^{2}$ lan Ford, director,, $\mathrm{C}$ David Batty, Wellcome Trust fellow, ${ }^{3,4,5}$ Harry Burns, chief medical officer for Scotland, ${ }^{6}$ Jonathan Cavanagh, senior lecturer in psychiatry, ${ }^{7}$ Eric de Groot, medical director of research and development, ${ }^{8}$ Agnes McGinty, research sister, ${ }^{1}$ Keith Millar, professor of medical psychology, ${ }^{9}$ Paul G Shiels, senior lecturer, ${ }^{10}$ Carol Tannahill, director, ${ }^{11}$ Yoga N Velupillai, public health programme manager, ${ }^{11}$ Naveed Sattar, professor of metabolic medicine, ${ }^{12}$ Chris I Packard, professor of vascular biochemistry?
\end{abstract}

'Department of Vascular
Biochemistry, Glasgow Royal
Infirmary, Glasgow G31 2ER

${ }^{2}$ Robertson Centre for Biostatistics, University of Glasgow, Glasgow G12 8QQ ${ }^{3}$ Medical Research Council Social and Public Health Sciences Unit, Glasgow G12 8RZ

${ }^{4}$ The George Institute for International Health, University of Sydney, Sydney, Australia

${ }^{5}$ Centre for Cognitive Ageing and Cognitive Epidemiology, University of Edinburgh, Edinburgh EH8 9JZ

${ }^{6}$ Scottish Government, Edinburgh EH1 3DG

${ }^{7}$ Sackler Institute of

Psychobiological Research, Section of Psychological Medicine, Medical Faculty—University of Glasgow, Glasgow G51 4TF

${ }^{8}$ Department of Vascular Medicine and Vascular Imaging, Academic Medical Centre, University of Amsterdam, Amsterdam, The Netherlands

${ }^{9}$ Section of Psychological Medicine, Medical FacultyUniversity of Glasgow, Glasgow G12 OXH

${ }^{10}$ University Department of Surgery, Faculty of Medicine, University of Glasgow, Glasgow Royal Infirmary, Glasgow G31 2ER

${ }^{11}$ Glasgow Centre for Population Health, Glasgow G2 4DL

${ }^{12}$ Division of Cardiovascular and Medical Sciences, University of

Glasgow, Glasgow Royal

Infirmary, Glasgow G31 2ER

Correspondence to: K A Deans

kevindeans@nhs.net

Cite this as: $B M J$ 2009;339:b4170 doi:10.1136/bmj.b4170

\section{ABSTRACT}

Objectives To examine the relation between area level social deprivation and ultrasound markers of atherosclerosis (common carotid intima-media thickness and plaque score), and to determine whether any differences can be explained by "classic" (currently recognised) or "emerging" (novel) cardiovascular risk factors.

Design Cross sectional, population based study. Setting NHS Greater Glasgow Health Board area. Participants 666 participants were selected on the basis of how their area ranked in the Scottish Index of Multiple Deprivation 2004. Approximately equal numbers of participants from the most deprived areas and the least deprived areas were included, as well as equal numbers of men and women and equal numbers of participants from each age group studied (35-44, 45-54, and 55-64 years).

Main outcome measures Carotid intima-media thickness and plaque score, as detected by ultrasound.

Results The mean age and sex adjusted intima-media thickness was significantly higher in participants from the most deprived areas than in those from the least deprived areas $(0.70 \mathrm{~mm}$ (standard deviation (SD) $0.16 \mathrm{~mm}) \mathrm{v}$ $0.68 \mathrm{~mm}$ (SD $0.12 \mathrm{~mm}$ ); $\mathrm{P}=0.015)$. On subgroup analysis, however, this difference was only apparent in the highest age tertile in men (56.3-66.5 years). The difference in unadjusted mean plaque score between participants from the most deprived and those from the least deprived areas was more striking than the difference in intimamedia thickness (least deprived 1.0 (SD 1.5) $v$ most deprived 1.7 (SD 2.0); P<0.0001). In addition, a significant difference in plaque score was apparent in the two highest age tertiles in men (46.8-56.2 years and 56.3-66. 5 years; $P=0.0073$ and $P<0.001$ ) and the highest age tertile in women (56.3-66.5 years; $P<0.001)$. The difference in intima-media thickness between most deprived and least deprived males remained significant after adjustment for classic risk factors, emerging risk factors, and individual level markers of socioeconomic status ( $P=0.010)$. Adjustment for classic risk factors and emerging cardiovascular risk factors, either alone or in combination, did not abolish the deprivation based difference in plaque presence (as a binary measure; adjusted odds ratio of $1.73,95 \%$ confidence interval 1.07 to 2.82). However, adjustment for classic risk factors and individual level markers of early life socioeconomic status abolished the difference in plaque presence between the most deprived and the least deprived individuals (adjusted odds ratio $0.94,95 \% \mathrm{Cl} 0.54$ to 1.65 ; $\mathrm{P}=0.84$ ). Conclusions Deprivation is associated with increased carotid plaque score and intima-media thickness. The association of deprivation with atherosclerosis is multifactorial and not adequately explained by classic or emerging risk factors.

\section{INTRODUCTION}

Ill health has long been recognised as more prevalent in areas of relative social deprivation, ${ }^{1-5}$ as exemplified by the higher incidence of coronary heart disease in areas of socioeconomic deprivation compared with socioeconomically advantaged areas. ${ }^{6-8}$ Although "classic" (currently recognised) risk factors go some way toward explaining this gradient, ${ }^{9}$ they do not explain all the difference. ${ }^{1011}$ This point was demonstrated by a 25 year follow-up of civil servants in the first Whitehall study, which showed that only one third of the differences in mortality between employment grades could be explained by differences in cholesterol, smoking, systolic blood pressure, impaired glucose tolerance, and diabetes. ${ }^{12}$ In recent years, novel biomarkers associated with insulin resistance, inflammation, and endothelial dysfunction have emerged as potential cardiovascular risk factors. ${ }^{13}$ However, whether any of these markers helps explain the socioeconomic gradient in coronary heart disease remains to be seen. 
Carotid ultrasound is an efficient validated tool for assessing the degree of atherosclerosis in an individual. Measurement of the artery wall intima-media thickness is a commonly used index of atherosclerosis. A recent systematic review and meta-analysis showed that the age and sex adjusted relative risk for myocardial infarction increases by 1.15 (95\% confidence interval 1.12 to 1.17 ) for every $0.10 \mathrm{~mm}$ increase in carotid intima-media thickness. ${ }^{14}$ The adjusted relative risk for stroke increases by 1.18 (95\% CI 1.16 to 1.21$)$ for every $0.10 \mathrm{~mm}$ increase in carotid intima-media thickness.

Ultrasound detection of carotid plaques is also highly informative. ${ }^{15}$ Plaque score has been shown to be associated with risk of myocardial infarction ${ }^{16-18}$ and stroke. ${ }^{19}$ In the Rotterdam study, the hazard ratio for myocardial infarction for a plaque score of three or more compared with one of zero was 1.83 (95\% CI 1.27 to 2.62$),{ }^{16}$ and the age and sex adjusted relative risk for stroke was 1.61 (95\% CI 1.16 to 2.23) for the highest tertile of plaque score compared with the lowest tertile. ${ }^{19}$

Given current understanding of the process of atherogenesis, carotid plaque presence is a more mechanistically plausible marker of atherosclerosis than is carotid intima-media thickness. Previous studies have suggested that plaque presence is indeed more strongly predictive of future cardiovascular events-specifically acute myocardial infarction - than intima-media thickness. ${ }^{2021}$ The American Society of Echocardiography has recognised a clinical role for measurement of intima-media thickness and detection of plaques in refining cardiovascular risk assessment in asymptomatic patients assessed as being at intermediate cardiovascular risk. $^{22}$

Several studies have examined the relation between socioeconomic status and ultrasound markers of atherosclerosis. Most studies have examined individual level measures of socioeconomic position (for example, income, education, occupation, housing tenure) and their relation to carotid intima-media thickness. ${ }^{23-29}$ Rosvall et al, however, studied a population based sample of 4033 individuals and found significant associations between area level deprivation and carotid plaque score. ${ }^{30}$ These associations were only slightly reduced on adjusting for individual level markers of socioeconomic position. Similarly, a study in Pittsburgh, Pennsylvania, found associations between community level socioeconomic status and both carotid intima-media thickness and carotid plaque occurrence. ${ }^{31}$ The association with plaque occurrence persisted after adjusting for individual level markers of socioeconomic status.

Glasgow, Scotland, provides an ideal setting for detailed investigation into associations between social deprivation and cardiovascular disease. At community level (the level of primary care localities, each with an average population of 70000 people), life expectancy at birth for men is 63.5 years in the most deprived parts of the city and 78.7 years in the least deprived areas. At postcode sector level (average population 3000-5000 individuals), the difference in life expectancy for men between most and least deprived groups is 28.7 years. ${ }^{32}$

The aim of this study was to enhance our understanding of the factors underlying associations between deprivation and ill health, with particular emphasis on atherosclerosis. We measured a wide range of "classic" and "emerging" cardiovascular risk factors, with a view to examining variables that could potentially explain the difference in prevalence of cardiovascular disease between most and least deprived populations. Our hypothesis was that social deprivation would be associated with higher common carotid intima-media thickness and/or plaque score, but that adjustment for emerging risk factors, especially inflammatory markers, would account for such differences.

\section{METHODS}

\section{Study population}

The design of the psychological, social, and biological determinants of ill health (pSoBid) study-including recruitment strategy, response rates, and study protocol-has been described in detail elsewhere. ${ }^{33}$ Selection of participants was based on the Scottish Index of Multiple Deprivation 2004, ${ }^{34}$ which ranks small areas on the basis of multiple deprivation indicators across six domains, namely: income; employment; health; education, skills, and training; geographic access and telecommunications; and housing. The measures in the Scottish Index of Multiple Deprivation permit identification of the least and most deprived areas in the NHS Greater Glasgow Health Board area.

Five general practices with the highest percentage of patients aged 35-64 years living in areas classified as being in the bottom $5 \%$ of all areas classed by the Scottish Index of Multiple Deprivation (that is, the most deprived areas) were approached, and all agreed to participate in the recruitment process. A further five practices with the highest percentage of patients aged 35-64 years living in areas classified as being in the top $20 \%$ of the Scottish Index of Multiple Deprivation (that is, the least deprived areas) also agreed to participate.

The health information and technology section of NHS Greater Glasgow Health Board generated a target population of 21672 people from the lists of these 10 practices. From this target population, 12 groups of 300 participants were selected according to strata defined by the combination of home address, Scottish Index of Multiple Deprivation classification, gender, and age group (35-44, 45-54, and 55-64 years). The total sampling frame comprised 3600 participants.

The sampling frame was constructed from general practice lists and, therefore, included individuals regardless of whether they actually visited their general practitioner. As the study progressed, oversampling of the most deprived group was required owing to a lower response rate. The health information technology section was approached to randomly select further potential participants from the target population. We recruited approximately equal numbers from the most and the least deprived areas, equal numbers of 
men and women, and equal numbers from each age group studied.

\section{Study protocol}

Participant visits were conducted between December 2005 and May 2007, with participants attending for two visits generally about two weeks apart. In visit one, participants completed lifestyle and psychology questionnaires and underwent measurement of blood pressure; heart rate; hip, waist, and mid-thigh circumference; and lung function.

For visit two, participants undertook a 10-12 hour fast and subsequently provided blood samples for biochemical analyses. All blood samples were separated and frozen at $-80^{\circ} \mathrm{C}$ within 1 hour of venepuncture. The exception was samples to be tested for cholesterol, triglycerides, low density lipoprotein, high density lipoprotein, apolipoproteins $\mathrm{A} 1$ and $\mathrm{B}, \mathrm{C}$ reactive protein, and glucose, which were analysed on fresh plasma.

Height and weight were also measured at visit two. After being provided with breakfast, participants completed psychological and cognitive tests. Finally, carotid ultrasound was performed.

All scans were performed on an ACUSON Sequoia 512 Ultrasound System with an L7 5-12 MHz linear array broadband transducer (Siemens Medical Solutions, Erlangen, Germany). The majority of the scans were performed by the same research nurse, who was trained in ultrasound techniques at the Department of Vascular Medicine, Academic Medical Centre, Amsterdam, The Netherlands. As prespecified in the study protocol, research nurses performing ultrasonography were required to complete a minimum of 10 paired replicate volunteer scans before scanning participants. Quality of images and reproducibility of intima-media thickness measurements from paired scans were assessed by the Department of Vascular Medicine. Research nurses had to meet predefined reproducibility criteria to be permitted to carry out study scans. Further paired replicate scans of volunteers were performed at intervals throughout the study to demonstrate continued fulfilment of the quality criteria.

Both left and right carotid arteries were assessed. The protocol involved initially measuring Doppler velocity in the internal carotid artery to exclude significant stenosis. Thereafter, B mode still images and dynamic clips were recorded of the distal $1 \mathrm{~cm}$ of the common carotid artery, the carotid bulb, and the proximal internal carotid artery on both sides. Finally, an M mode image of wall movement in the distal $1 \mathrm{~cm}$ of the common carotid artery was recorded over at least two cardiac cycles to allow assessment of arterial stiffness. Each scan was saved as a Digital Imaging and Communications in Medicine file.

Scans were analysed using the eTrack software provided by the Department of Vascular Medicine and Physiology, Academic Medical Centre, Amsterdam, The Netherlands. All scans were analysed by the same reader, who was blinded to the identities of the participants. Reader reproducibility was assessed by repeat reading of a proportion of the scans. Repeat reads were consistently within the predefined certification limits of a coefficient of variation of $\leq 5 \%$.

\section{Outcome measures}

The prespecified primary outcome was mean common carotid intima-media thickness. Intima-media thickness was measured on the far wall of each arterial segment, averaged along a $1 \mathrm{~cm}$ length or as much as was able to be read. The secondary outcome was plaque score,${ }^{16}$ which was determined by counting the number of plaques. A plaque was defined as a focal structure encroaching into the arterial lumen by at least $0.5 \mathrm{~mm}$ or by $50 \%$ of the surrounding intima-media thickness, or demonstrating a thickness $>1.5 \mathrm{~mm}$ as measured from media-adventitia interface to intima-lumen interface. ${ }^{15}$ Plaque count was then converted into a plaque score by dividing this value by the number of readable images present and multiplying the outcome by 6 (the maximum possible number of images per participant), ${ }^{16}$ thus adjusting for unreadable images.

\section{Analysis of risk factors \\ Circulating markers}

Classic risk factors-Cholesterol and triglyceride concentrations were determined by enzymatic colorimetric assays on a Roche Hitachi 917 analyser (Roche Diagnostics Ltd, Burgess Hill, UK). Lipid fractions were measured using ultracentrifugation and precipitation methods. ${ }^{35}$ Glucose was measured by hexokinase and glucose-6-phosphate dehydrogenase assay on an Abbott c8000 analyser (Abbott Diagnostics, Maidenhead, UK).

Emerging risk factors-Insulin and adiponectin were measured by sandwich enzyme linked immunosorbent assay (Mercodia AB, Uppsala, Sweden and ALPCO Diagnostics, Salem, NH, USA, respectively). Leptin was measured by an in-house radioimmunoassay validated against a commercially available radioimmunoassay (Linco Research Inc, St Louis, $\mathrm{MO}, \mathrm{USA}) .{ }^{36}$ High sensitivity $\mathrm{C}$ reactive protein was measured by an immunoturbidimetric assay (Roche Diagnostics Ltd). Interleukin 6 and intercellular adhesion molecule 1 were measured by sandwich enzyme linked immunosorbent assay (R\&D Systems Europe Ltd, Abingdon, UK). von Willebrand factor was measured using an in-house enzyme linked immunosorbent assay, employing rabbit anti-human polyclonal antibodies (DAKO UK Ltd, Ely, UK). Fibrinogen was measured on an automated coagulometer (MDA180; Organon Teknika, Cambridge, UK). D-dimer and tissue plasminogen activator antigen were measured by enzyme linked immunosorbent assay (Hyphen, Neuville-sur-Oise, France).

\section{Physical activity}

Questions on habitual physical activity at work and in recreation were included in the lifestyle questionnaire, 
Table 1 |Characteristics of study participants

\begin{tabular}{|c|c|c|c|c|}
\hline & $\begin{array}{l}\text { Least deprived } \\
\quad(\mathrm{n}=342)\end{array}$ & $\begin{array}{l}\text { Most deprived } \\
(\mathrm{n}=324)\end{array}$ & $\begin{array}{l}\text { Least minus most deprived } \\
\text { (adjusted for age and sex( } 95 \% \mathrm{Cl}) \text { ) }\end{array}$ & P value \\
\hline \multicolumn{5}{|l|}{ Markers of individual socioeconomic status } \\
\hline Height $(\mathrm{cm})$ & $171.0(9.4)$ & $165.0(8.7)$ & $5.72(4.77$ to 6.66$)$ & $<0.0001$ \\
\hline Data missing & $2(0)$ & $1(0)$ & & \\
\hline Leg length $(\mathrm{cm})$ & $81.9(6.0)$ & $78.7(5.4)$ & 3.07 (2.31 to 3.83$)$ & $<0.0001$ \\
\hline Data missing & $41(0)$ & $21(0)$ & & \\
\hline People per room at age 11 years & $1.2(0.5)$ & $1.8(0.9)$ & $-0.67(-0.78$ to -0.56$)$ & $<0.0001$ \\
\hline Data missing & $0(0)$ & $2(0)$ & & \\
\hline Father's Registrar General social class & & & & $<0.0001$ \\
\hline 0 Data not classifiable & $15(4 \%)$ & $17(5 \%)$ & & \\
\hline I Professional & $30(9 \%)$ & $1(0.3 \%)$ & & \\
\hline II Managerial \& technical & $130(38 \%)$ & $27(8 \%)$ & & \\
\hline IIIN Skilled non-manual & $30(9 \%)$ & $13(4 \%)$ & & \\
\hline IIIM Skilled manual & $98(29 \%)$ & $155(48 \%)$ & & \\
\hline IV Partly skilled & $22(7 \%)$ & $43(13 \%)$ & & \\
\hline V Unskilled & $10(3 \%)$ & $42(13 \%)$ & & \\
\hline Unknown to participant & $4(1 \%)$ & $16(5 \%)$ & & \\
\hline Unemployed & $1(0.3 \%)$ & $10(3 \%)$ & & \\
\hline Data missing & $2(0)$ & $0(0)$ & & \\
\hline Participant's Registrar General social class & & & & $<0.0001$ \\
\hline 0 Data not classifiable & $1(0.3 \%)$ & $16(5 \%)$ & & \\
\hline I Professional & $58(17 \%)$ & $5(2 \%)$ & & \\
\hline II Managerial \& technical & $193(57 \%)$ & $57(18 \%)$ & & \\
\hline IIIN Skilled non-manual & 59 (17\%) & $52(16 \%)$ & & \\
\hline IIIM Skilled manual & $16(5 \%)$ & $87(27 \%)$ & & \\
\hline IV Partly skilled & $10(3 \%)$ & $70(22 \%)$ & & \\
\hline V Unskilled & $2(0.6 \%)$ & $35(11 \%)$ & & \\
\hline Unemployed & $1(0.3 \%)$ & $2(0.6 \%)$ & & \\
\hline Data missing & $2(0)$ & $0(0)$ & & \\
\hline Annual household income & & & & $<0.0001$ \\
\hline «15 000 & $12(4 \%)$ & $186(57 \%)$ & & \\
\hline$£ 16-25000$ & $29(9 \%)$ & $78(24 \%)$ & & \\
\hline$£ 26-35000$ & $40(12 \%)$ & $21(7 \%)$ & & \\
\hline$£ 36-45000$ & $44(13 \%)$ & $13(4 \%)$ & & \\
\hline 泛 5000 & $187(55 \%)$ & $10(3 \%)$ & & \\
\hline Data missing & $30(0)$ & $16(0)$ & & \\
\hline Total education (years) & $16.1(3.6)$ & $11.8(2.5)$ & $4.32(3.85$ to 4.79$)$ & $<0.0001$ \\
\hline Data missing & $0(0)$ & $0(0)$ & & \\
\hline \multicolumn{5}{|l|}{ Classic risk factors (behavioural) } \\
\hline \multicolumn{5}{|l|}{ Smoking } \\
\hline Ever smoked regularly & $121(35.4 \%)$ & $241(74.4 \%)$ & $12.07(7.33$ to 19.88$) \dagger$ & $<0.0001$ \\
\hline Current cigarette smoker & $21(6.1 \%)$ & $131(40.4 \%)$ & & \\
\hline Data missing & $0(0)$ & $0(0)$ & & \\
\hline Physical activity & & & & $<0.0001$ \\
\hline Inactive & $82(24 \%)$ & $160(49 \%)$ & & \\
\hline Moderately inactive & $84(25 \%)$ & $37(11 \%)$ & & \\
\hline Moderately active & $87(25 \%)$ & $71(22 \%)$ & & \\
\hline Active & $89(26 \%)$ & $56(17 \%)$ & & \\
\hline Data missing & $0(0)$ & $0(0)$ & & \\
\hline \multicolumn{5}{|l|}{ Classic risk factors (physiological) } \\
\hline Cholesterol (mmol/l) & $5.29(1.03)$ & $4.95(1.05)$ & 0.35 (0.19 to 0.51$)$ & $<0.0001$ \\
\hline Data missing & $7(0)$ & $14(0)$ & & \\
\hline Triglycerides (mmol/l) & 1.19 & 1.44 & $-0.20(-0.27$ to -0.12$) \ddagger$ & $<0.0001$ \\
\hline Data missing & $7(0)$ & $14(0)$ & & \\
\hline Low density lipoprotein cholesterol (mmol/l) & $3.16(0.87)$ & $2.86(0.88)$ & $0.31(0.17$ to 0.44$)$ & $<0.0001$ \\
\hline Data missing & $7(0)$ & $18(0)$ & & \\
\hline High density lipoprotein cholesterol (mmol/l) & $1.43(0.38)$ & $1.30(0.39)$ & 0.13 (0.08 to 0.19$)$ & $<0.0001$ \\
\hline
\end{tabular}




\begin{tabular}{|c|c|c|c|c|}
\hline & $\begin{array}{l}\text { Least deprived } \\
\qquad(n=342)\end{array}$ & $\begin{array}{l}\text { Most deprived } \\
\quad(n=324)\end{array}$ & $\begin{array}{l}\text { Least minus most deprived } \\
\text { (adjusted for age and } \operatorname{sex}(95 \% \mathrm{Cl}) \text { ) }\end{array}$ & $P$ value \\
\hline Data missing & $7(0)$ & $14(0)$ & & \\
\hline Glucose (mmol/l) & $5.15(0.69)$ & $5.42(1.90)$ & $-0.41(-0.69$ to -0.14$)$ & 0.0088 \\
\hline Data missing & $19(7)$ & $35(16)$ & & \\
\hline Weight (kg) & $78.7(15.3)$ & $78.2(18.4)$ & $0.34(-2.06$ to 2.74$)$ & 0.78 \\
\hline Data missing & $1(0)$ & $1(0)$ & & \\
\hline Waist/hip ratio & $0.88(0.08)$ & $0.92(0.09)$ & $-0.04(-0.05$ to -0.03$)$ & $<0.0001$ \\
\hline Data missing & $3(1)$ & $4(2)$ & & \\
\hline BMI & $26.9(4.49)$ & $28.7(6.34)$ & $-1.81(-2.64$ to -0.98$)$ & $<0.0001$ \\
\hline Data missing & $2(0)$ & $2(0)$ & & \\
\hline Blood pressure (mm Hg) & $135(17.8) / 81.4(10.3)$ & $136(20.0) / 81.1(11.6)$ & $-0.75(-3.44$ to 1.93$) / 0.27(-1.32$ to 1.87$)$ & $0.58 / 0.74$ \\
\hline Data missing & $2(0)$ & $2(0)$ & & \\
\hline \multicolumn{5}{|l|}{ Emerging risk factors: insulin resistance/fat mass } \\
\hline Insulin (mU/l) & $6.62(4.91)$ & $7.72(5.97)$ & $-1.81(-3.29$ to -0.34$)$ & 0.011 \\
\hline Data missing & $18(8)$ & $41(26)$ & & \\
\hline $\begin{array}{l}\text { Homeostasis model of assessment-insulin resistance (HOMA- } \\
\text { IR) }\end{array}$ & $1.52(1.22)$ & $1.81(1.60)$ & $-0.80(-1.15$ to -0.44$)$ & 0.015 \\
\hline Data missing & $24(10)$ & $49(31)$ & & \\
\hline Leptin (ng/ml) & $18.7(16.8)$ & $23.7(24.0)$ & $-4.46(-7.24$ to -1.67$)$ & 0.0017 \\
\hline Data missing & $14(0)$ & $20(0)$ & & \\
\hline \multicolumn{5}{|l|}{ Emerging risk factors: inflammation/endothelial dysfunction } \\
\hline C reactive protein (mg/l) & 1.16 & 2.07 & $-0.57(-0.74$ to -0.41$) \ddagger$ & $<0.0001$ \\
\hline Data missing & $11(4)$ & $19(5)$ & & \\
\hline Interleukin 6 (pg/ml) & 1.36 & 2.08 & $-0.43(-0.53$ to -0.33$) \ddagger$ & $<0.0001$ \\
\hline Data missing & $13(3)$ & $24(8)$ & & \\
\hline Intercellular adhesion molecule 1 (ng/ml) & 235.8 & 302.4 & $-0.25(-0.29$ to -0.21$) \ddagger$ & $<0.0001$ \\
\hline Data missing & $10(0)$ & $20(4)$ & & \\
\hline \multicolumn{5}{|l|}{ Emerging risk factors: haemostasis } \\
\hline von Willebrand factor (IU/dl) & $129(39)$ & $155(47)$ & $-26(-33$ to -20$)$ & $<0.0001$ \\
\hline Data missing & $8(0)$ & $23(0)$ & & \\
\hline Fibrinogen (g/l) & $3.23(0.60)$ & $3.50(0.80)$ & $-0.26(-0.36$ to -0.15$)$ & $<0.0001$ \\
\hline Data missing & $10(0)$ & $23(0)$ & & \\
\hline D-dimer (ng/ml) & $130(97)$ & $155(102)$ & $-24(-39$ to -8.9$)$ & 0.0018 \\
\hline Data missing & $8(0)$ & $23(0)$ & & \\
\hline \multicolumn{5}{|c|}{$\begin{array}{l}\text { Descriptive statistics are presented as mean (standard deviation) for continuous variables and count (\%) for categorical outcomes. Geometric means are shown for triglycerides, } C \text { reactive } \\
\text { protein, interleukin } 6 \text {, and intercellular adhesion molecule } 1 . \\
\text { In "Data missing" fields, figures in brackets indicate the number of values that were removed on the basis of known pre-analytical factors or biological implausibility. } \\
\text { †Odds ratio. } \\
\text { †Difference of logged parameters. }\end{array}$} \\
\hline
\end{tabular}

allowing participants to be classified as inactive, moderately inactive, moderately active, or active using a previously validated protocol. ${ }^{37}$

\section{Statistical analysis}

The size of the sample required from the most deprived areas and that from the least deprived areas was estimated on the assumption that $90 \%$ of participants would attend both study visits and have $\mathrm{C}$ reactive protein measured, and that a maximum of $10 \%$ would not have a carotid ultrasound scan of satisfactory quality for measurement of intima-media thickness. Power calculations were based on perceived clinically meaningful differences between the two groups and assumed a $1.1 \mathrm{mg} / \mathrm{l}$ standard deviation for the natural logarithm of $\mathrm{C}$ reactive protein measurement ${ }^{38}$ and a $0.163 \mathrm{~mm}$ standard deviation for intima-media thickness. ${ }^{39}$ These calculations indicated that a sample size of 350 per group would provide $84 \%$ power to detect a $30 \%$ difference in mean $\mathrm{C}$ reactive protein concentration and $82 \%$ power to detect a $0.04 \mathrm{~mm}$ difference in mean intima-media thickness.

Descriptive statistics are presented as mean (standard deviation) for continuous variables and count $(\%)$ for categorical outcomes. Variables with positively skewed distributions (triglycerides, $\mathrm{C}$ reactive protein, interleukin 6 , and intercellular adhesion molecule 1) are described by geometric means and log transformation was used for regression analysis. For comparisons of population characteristics between deprivation groups, analysis of covariance was used for continuous variables and logistic regression analyses for binary responses. The results were presented as adjusted means for "least" deprived minus "most" deprived and odds ratios for least deprived versus most deprived categories, respectively. Cut-off points for logistic regression were selected on the following basis: annual income was categorised using the categories in the 
Table 2|Differences in ultrasound markers of atherosclerosis between participants from the most deprived areas and those from the least deprived areas

\begin{tabular}{lcccc} 
& $\begin{array}{c}\text { Least } \\
\text { deprived } \\
(\mathrm{n}=342)\end{array}$ & $\begin{array}{c}\text { Most } \\
\text { deprived } \\
(\mathrm{n}=324)\end{array}$ & $\begin{array}{c}\text { Least minus most deprived } \\
\text { (adjusted for age and sex } \\
(95 \% \mathrm{Cl}))\end{array}$ & P value \\
$\begin{array}{lccc}\text { Mean (SD) carotid intima-media } \\
\text { thickness (mm) }\end{array}$ & $0.68(0.12)$ & $0.70(0.16)$ & $-0.02(-0.04$ to -0.00$)$ & 0.015 \\
\hline Data missing & 23 & 29 & $<0.0001^{*}$ \\
\hline Mean (SD) plaque score & $1.0(1.5)$ & $1.7(2.0)$ & $<0.0001$ \\
\hline Number of plaques (\%) & & & for trend* \\
\hline 0 plaques & $193(56.9 \%)$ & $130(41.7 \%)$ & \\
\hline 1-2 plaques & $101(29.8 \%)$ & $89(28.5 \%)$ & & \\
\hline 2 plaques & $45(13.3 \%)$ & $93(29.8 \%)$ & & \\
\hline Data missing & 3 & 12 & & \\
\hline
\end{tabular}

*Not adjusted for age and sex.

\section{RESULTS}

Overall, 2712 invitations to participate were issued and 666 individuals completed both study visits, giving an overall response rate of $24.6 \%$. The least deprived group thus comprised 175 men and 167 women, and the most deprived group consisted of 159 men and 165 women. Only 19 participants $(2.9 \%)$ were born outside the United Kingdom and the Republic of Ireland (14 from the least deprived group and five from the most deprived group).

The response rate for the least deprived group was $33.9 \%$ and for the most deprived group was 19.0\%. When participants were stratified by deprivation category (most deprived or least deprived), gender (male or female), and age (35-44 years, 45-54 years, or $55-64$ years), response rate varied from $13.6 \%$ in men aged 35-44 years in the most deprived group to $51.2 \%$ in men aged 55-64 years in the least deprived group. Full details of response rates have been published previously. $^{33}$

\section{Comparison of participants and non-participants}

In order to compare the characteristics of individuals who took part in the study and those who did not, anonymised data were extracted from the General Practice Administration System for Scotland, ${ }^{40}$ which was used by eight of the 10 practices from which participants were drawn (four in the least deprived areas and four in the most deprived areas). Data were obtained from the database on smoking status and current prescriptions for statins, aspirin, antihypertensives, antidepressants, and antidiabetic drugs. Data were collected separately for individuals who attended visit one (group one, $\mathrm{n}=700$ ), those who declined to attend
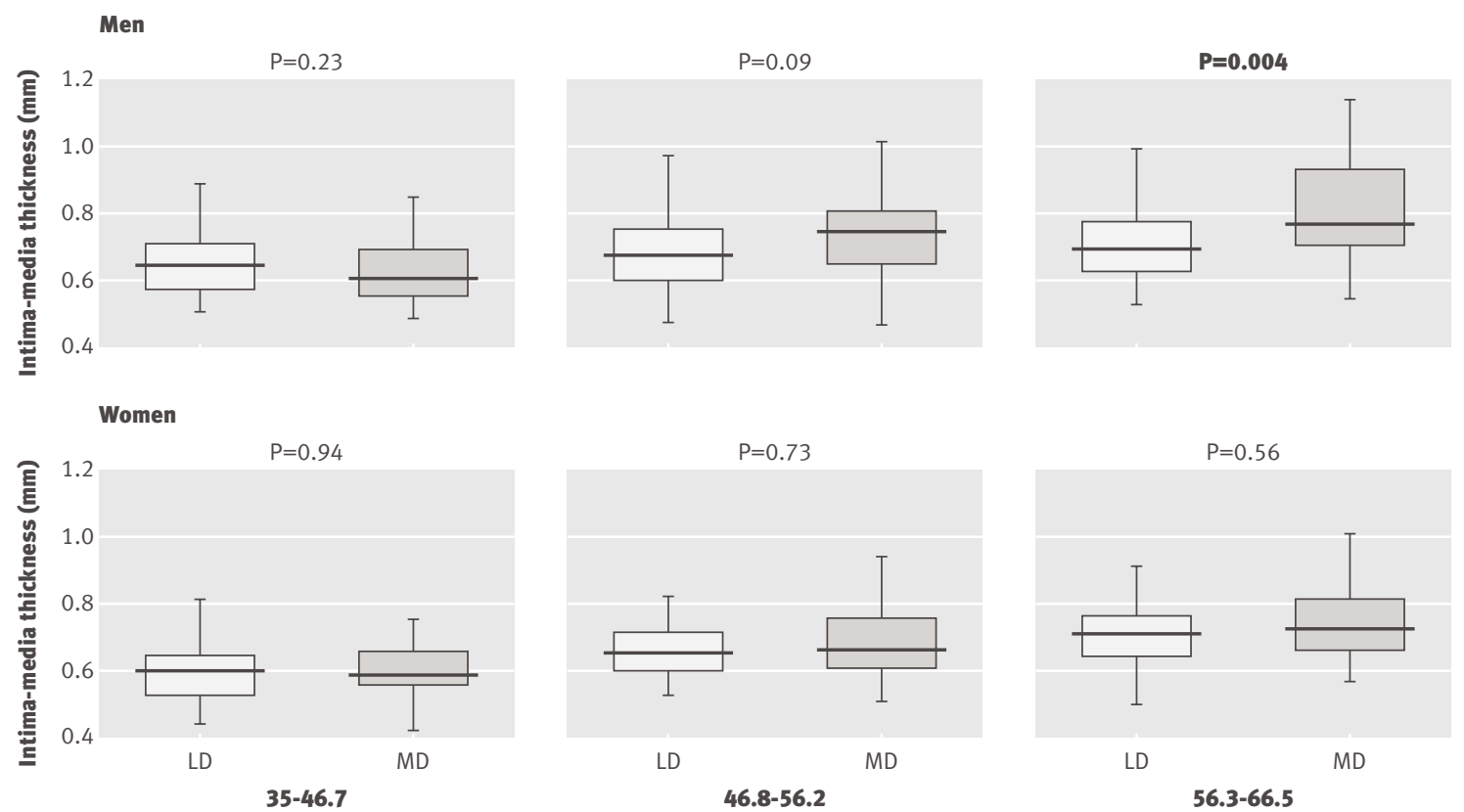

56.3-66.5

Age (years)

Fig 1 | Intima-media thickness by age tertile and deprivation category. $L D=$ least deprived, $M D=$ most deprived 

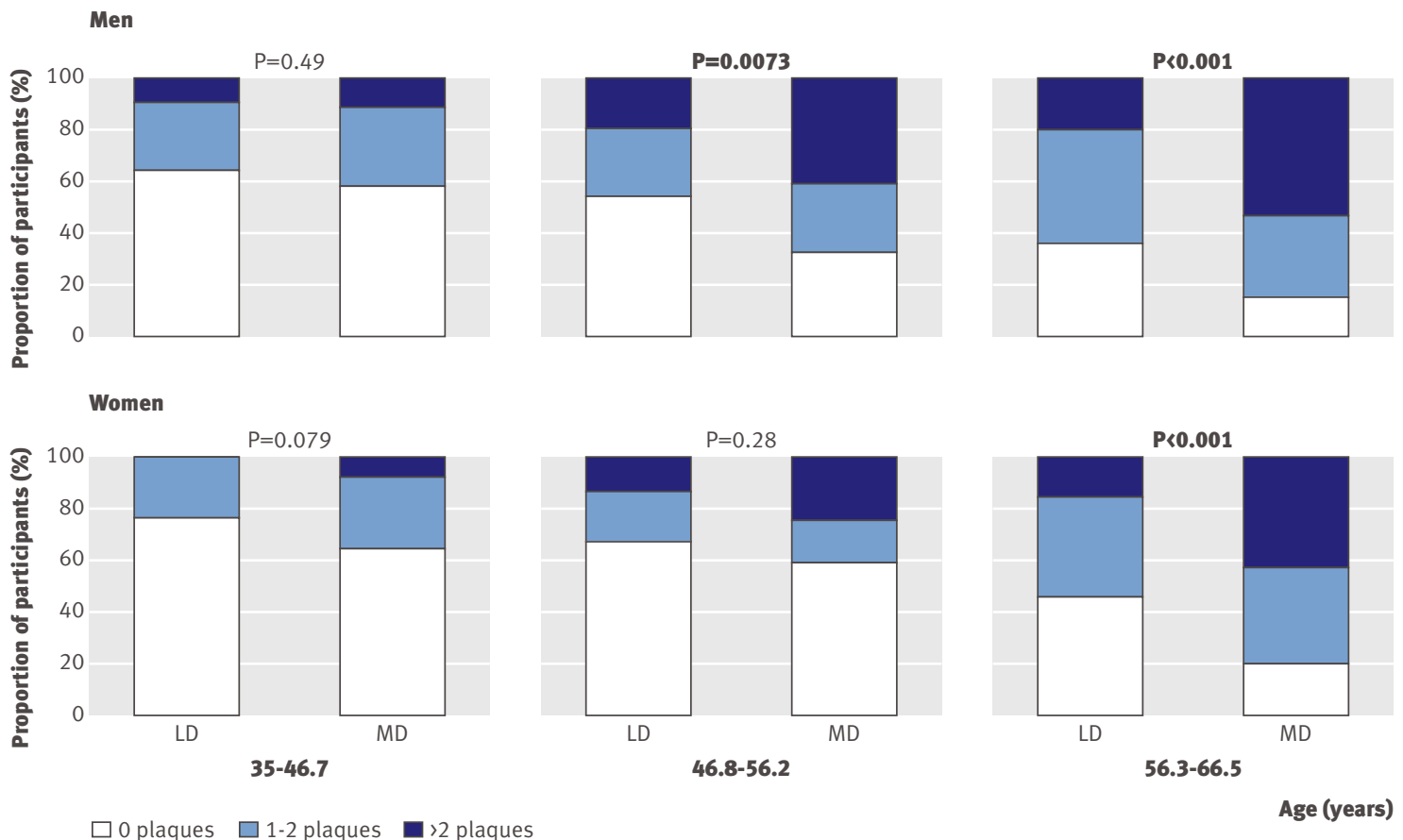

Age (years)

Fig 2 |Plaque score by age tertile and deprivation category. LD=least deprived, MD=most deprived

(group two, $\mathrm{n}=812$ ), and those who did not respond to the invitation (group three, $\mathrm{n}=1200$ ). Non-participants (group four, $\mathrm{n}=2012$ ) were defined as the combination of groups two and three.

In the least deprived group, more non-participants than participants were current smokers $(11.5 \%$ v 6.3\%; $\mathrm{P}=0.017)$. No such difference was observed in the most deprived group (non-participants who were current smokers $50.5 \%$ v participants who were current smokers $48.8 \% ; \mathrm{P}=0.6)$. Participants in both the least deprived and most deprived group were more likely than nonparticipants to be on statins (least deprived participants $8.8 \%$ v least deprived non-participants $5.0 \% ; \mathrm{P}=0.03$; most deprived participants 29.7\% v most deprived nonparticipants 15.5\%; $\mathrm{P}<0.0001$ ), antihypertensives (least deprived participants $18.2 \% \quad v$ least deprived non-participants $13.3 \% ; \quad \mathrm{P}=0.05 ;$ most deprived participants $34.8 \% v$ most deprived non-participants $24.5 \% ; \quad \mathrm{P}=0.0004)$, and antidiabetic medications (least deprived participants $2.8 \% \quad v$ least deprived non-participants $0.9 \% ; \quad \mathrm{P}=0.03 ;$ most deprived participants $8.5 \% \quad v$ most deprived non-participants $5.0 \% ; \mathrm{P}=0.02)$.

Characteristics of the least deprived and most deprived groups are shown in table 1 . Of note is the fact that the difference in total cholesterol between the least deprived and most deprived groups was highly statistically significant and the direction of difference was the opposite of what might intuitively be expected: total cholesterol was lower in the most deprived group than in the least deprived group $(4.95 \mathrm{mmol} / \mathrm{l} v$ $5.29 \mathrm{mmol} / \mathrm{l} ; \mathrm{P}<0.0001)$. High density lipoprotein cholesterol was lower in the most deprived group ( $1.30 \mathrm{mmol} / \mathrm{l}$ v $1.43 \mathrm{mmol} / \mathrm{l} ; \mathrm{P}<0.0001)$ as was low density lipoprotein $(2.86 \mathrm{mmol} / \mathrm{l} v 3.16 \mathrm{mmol} / \mathrm{l}$;
$\mathrm{P}<0.0001$ ), so the low density lipoprotein/high density lipoprotein ratio did not differ between the two groups (mean of 2.37 in both; $\mathrm{P}=0.91$ ). The differences in lipoprotein concentrations persisted after adjustment for the use of lipid lowering therapy $(21.3 \%$ of most deprived participants and 5.3\% of least deprived participants were on statin therapy; adjusted $\mathrm{P}=0.049$ for total cholesterol and $\mathrm{P}=0.00025$ for high density lipoprotein).

Blood pressure did not differ between the two groups, and, as expected, current smoking differed considerably, with the proportion of current smokers in the most deprived group significantly higher than that in the least deprived group (40.4\% v 6.1\%).

Indices of insulin resistance and dysglycaemia (fasting glucose and insulin concentrations, and Homeostasis Model of Assessment [HOMA-IR]) and obesity (waist/hip ratio, BMI, and leptin concentration) were significantly higher in the most deprived group $(\mathrm{P}<0.05$ for all; table 1$)$. The difference in adiponectin concentration between the two groups was not significant (data not shown).

Markers of chronic inflammation and endothelial dysfunction ( $\mathrm{C}$ reactive protein, interleukin 6 , intercellular adhesion molecule 1 , and von Willebrand factor) were significantly different between the two groups (all $\mathrm{P}<0.0001)$. Fibrinogen and $\mathrm{D}$-dimer concentrations were higher in the most deprived category $(\mathrm{P}<0.0001$ and $\mathrm{P}=0.0018$, respectively), but no difference was observed in tissue plasminogen activator antigen concentration $(\mathrm{P}=0.18)$.

\section{Carotid ultrasound analysis}

Differences in ultrasound markers of atherosclerosis are shown in table 2 . The age and sex adjusted difference in 
Table $3 \mid$ Differences between men from the least deprived areas and those from the most deprived areas in gradient of mean common carotid intima-media thickness plotted against age

\begin{tabular}{|c|c|c|c|}
\hline & \multicolumn{2}{|l|}{ Gradient } & \multirow[b]{2}{*}{ F test $P$ value } \\
\hline & Mean difference $(95 \% \mathrm{Cl})$ & $P$ value & \\
\hline Model 1 (unadjusted) & $-0.07(-0.11$ to -0.02$)$ & 0.0059 & 0.0011 \\
\hline $\begin{array}{l}\text { Model } 2 \\
\text { (classic risk factors) }\end{array}$ & $-0.06(-0.11$ to -0.01$)$ & 0.021 & 0.031 \\
\hline $\begin{array}{l}\text { Model } 3 \\
\text { (classic+insulin resistance) }\end{array}$ & $-0.07(-0.12$ to -0.02$)$ & 0.008 & 0.017 \\
\hline $\begin{array}{l}\text { Model } 4 \\
\text { (classic+inflammatory) }\end{array}$ & $-0.06(-0.11$ to -0.01$)$ & 0.021 & 0.018 \\
\hline $\begin{array}{l}\text { Model } 5 \\
\text { (classic+haemostasis) }\end{array}$ & $-0.06(-0.11$ to -0.01$)$ & 0.02 & 0.037 \\
\hline $\begin{array}{l}\text { Model } 6 \\
\text { (classic+physical activity) }\end{array}$ & $-0.06(-0.11$ to -0.01$)$ & 0.018 & 0.026 \\
\hline $\begin{array}{l}\text { Model } 7 \\
\text { (classic+all "emerging"+physical } \\
\text { activity) }\end{array}$ & $-0.08(-0.13$ to -0.02$)$ & 0.0075 & 0.010 \\
\hline $\begin{array}{l}\text { Model } 8 \\
\text { (classic+individual socioeconomic } \\
\text { status (early life)) }\end{array}$ & $-0.06(-0.11$ to -0.01$)$ & 0.024 & 0.053 \\
\hline $\begin{array}{l}\text { Model } 9 \\
\text { (classic+individual socioeconomic } \\
\text { status (all)) }\end{array}$ & $-0.07(-0.12$ to -0.02$)$ & 0.01 & 0.03 \\
\hline $\begin{array}{l}\text { Model } 10 \\
\text { (classic+all) }\end{array}$ & $-0.1(-0.16$ to -0.03$)$ & 0.0025 & 0.010 \\
\hline
\end{tabular}

Model 1: not adjusted for other factors.

Model 2 (classic risk factors): adjusted for triglycerides, low density lipoprotein cholesterol, high density

lipoprotein cholesterol, systolic blood pressure, diastolic blood pressure, smoking, and history of hypertension. Model 3 (classic+insulin resistance markers): as Model 2+waist circumference, glucose, Homeostasis Model of Assessment-Insulin Resistance (HOMA-IR), adiponectin, leptin, and history of diabetes.

Model 4 (classic+inflammatory): as Model $2+C$ reactive protein, interleukin 6 , and intercellular adhesion molecule 1.

Model 5 (classic+haemostasis): as Model 2+fibrinogen, D-dimer, and von Willebrand factor.

Model 6 (classic+physical activity): as Model 2+physical activity.

Model 7 (classic+all "emerging"+physical activity): as Model 2+ waist circumference, glucose, Homeostasis Model of Assessment-Insulin Resistance, adiponectin, leptin, history of diabetes, $C$ reactive protein, interleukin 6 , intercellular adhesion molecule 1, fibrinogen, D-dimer, von Willebrand factor, and physical activity.

Model 8 (classic+individual socioeconomic status (early life)): as Model 2+height, leg length, people per room at age 11 years, father's Registrar General social class, and total years of education.

Model 9 (classic+individual socioeconomic status (all)): as Model 8+participant's Registrar General social class and annual household income.

Model 10 (classic+all): as Model 2+waist circumference, glucose, Homeostasis Model of Assessment-Insulin Resistance, adiponectin, leptin, history of diabetes, $C$ reactive protein, interleukin 6 , intercellular adhesion molecule 1, fibrinogen, D-dimer, von Willebrand factor, physical activity, height, leg length, people per room at age 11 years, father's Registrar General social class, participant's Registrar General social class, annual household income, and total years of education.

mean intima-media thickness between the most deprived group and the least deprived group was $0.02 \mathrm{~mm}(\mathrm{P}=0.015)$. When analysing men and women separately, the difference in mean intima-media thickness between participants in most and least deprived areas was statistically significant for men $(\mathrm{P}=0.044)$ but not for women $(\mathrm{P}=0.77)$.

Figures 1 and 2 show the differences in carotid intima-media thickness and plaque score for each gender, separately split by age tertile. The ages stated for each age tertile are the ages of the participants at the time of carotid ultrasound scan, by which point the participants were slightly older than they were at the time of original selection for the study. The expected increase in intima-media thickness with age is present; however, the difference in intima-media thickness between the most deprived group and the least deprived group only reached statistical significance in the highest age tertile (56.3-66.5 years) in men and did not achieve statistical significance in women at any age. By contrast, the difference in mean plaque score between the most deprived group and the least deprived group was highly significant in men in the two highest age tertiles (46.8-56.2 years and 56.3-66. 5 years; $\mathrm{P}=0.0073$ and $\mathrm{P}<0.001)$ and in women in the highest age tertile $(56.3-66.5$ years; $\mathrm{P}<0.001)$.

\section{Multivariate analyses for carotid intima-media thickness}

As planned in the study protocol, ${ }^{33}$ analyses were carried out to uncover potential explanations for the variation in intima-media thickness according to area level deprivation. Given that this difference was significant only in men when the genders were analysed separately, only men were included in these analyses.

The following variables listed in table 1 were significant correlates for age adjusted intima-media thickness: $\quad \log$ triglycerides (positive association; $\mathrm{P}=0.0092$ ); high density lipoprotein cholesterol (negative association; $\mathrm{P}=0.044)$; and systolic blood pressure (positive association; $\mathrm{P}=0.028$ ). A number of multivariate models were then constructed, with potential explanatory variables grouped according to category of risk marker (for example, classic risk factors, markers of insulin resistance, inflammatory markers, markers of haemostasis) and adjusted for in the analyses. When intima-media thickness was plotted against age, the gradient (representing rate of increase in intimamedia thickness with age) differed between men from the most and least deprived areas.

Table 3 shows the means and $\mathrm{P}$ values for the differences in the gradients of plots of mean common carotid intima-media thickness against age for most deprived and least deprived men, adjusted as described for each model. In addition, the $\mathrm{F}$ test $\mathrm{P}$ value is also given to take account of differential intercepts. Adjusting for the classic risk factors of age, triglycerides, low density lipoprotein cholesterol, high density lipoprotein cholesterol, systolic blood pressure, diastolic blood pressure, smoking, and history of hypertension (model 2) failed to attenuate the difference in intima-media thickness between most deprived men and least deprived men $(\mathrm{P}=0.031)$.

In further models, "emerging" risk factors representing insulin resistance, inflammatory factors, and haemostasis were adjusted for. Additionally, models incorporating physical activity and individual level markers of socioeconomic status were constructed. Finally, all variables were added simultaneously to a model. With all classic and emerging risk factors added, and individual level markers of socioeconomic status included, the difference in intima-media thick ness between most deprived and least deprived males remained significant (model 10; $\mathrm{P}=0.010)$.

\section{Multivariate analyses for plaque score}

On age and sex adjusted analyses, the following risk factors were significant predictors of plaque presence: $\log$ triglycerides $(\mathrm{P}=0.0016)$; systolic blood pressure $(\mathrm{P}=0.0079)$; diastolic blood pressure $(\mathrm{P}=0.049)$; current 
smoking $(\mathrm{P}<0.0001)$; log intercellular adhesion molecule $1(\mathrm{P}=0.00028)$; and fibrinogen $(\mathrm{P}=0.023)$. Height $(\mathrm{P}=0.00013)$ and hip circumference $(\mathrm{P}=0.00014)$ were inversely associated with plaque score.

Multivariate models were constructed using presence of plaque as the dependent variable. The analyses were run in all participants because plaque score was significantly different between most deprived and least deprived groups in both men and women. Plaque presence rather than plaque score was used as the dependent variable in these analyses because plaque score did not fit conventional distributions that might be used for regression analyses and it was decided that the binary approach to transformation would encompass most of the information in the data.

The results of multivariate analyses for plaque presence are shown in table 4 . In the model that adjusted for all classic and novel risk factors plus physical activity (model 7), the difference in plaque presence between the most deprived and the least deprived individuals remained significant (adjusted odds ratio 1.73,

\begin{tabular}{|c|c|c|}
\hline & Odds ratio $(95 \% \mathrm{Cl})$ & $P$ value \\
\hline Model 1 (age, sex, scans present) & 2.05 (1.45 to 2.89$)$ & $<0.0001$ \\
\hline $\begin{array}{l}\text { Model } 2 \\
\text { (classic risk factors) }\end{array}$ & 1.71 (1.14 to 2.55$)$ & 0.009 \\
\hline $\begin{array}{l}\text { Model } 3 \\
\text { (classic+insulin resistance) }\end{array}$ & $1.82(1.18$ to 2.80$)$ & 0.0066 \\
\hline $\begin{array}{l}\text { Model } 4 \\
\text { (classic+inflammatory) }\end{array}$ & 1.71 (1.11 to 2.65$)$ & 0.015 \\
\hline $\begin{array}{l}\text { Model } 5 \\
\text { (classic+haemostasis) }\end{array}$ & 1.77 (1.16 to 2.69$)$ & 0.0075 \\
\hline $\begin{array}{l}\text { Model } 6 \\
\text { (classic+physical activity) }\end{array}$ & $1.60(1.05$ to 2.41$)$ & 0.027 \\
\hline $\begin{array}{l}\text { Model } 7 \\
\text { (classic+all "emerging"+physical activity) }\end{array}$ & 1.73 (1.07 to 2.82$)$ & 0.026 \\
\hline $\begin{array}{l}\text { Model } 8 \\
\text { (classic+individual socioeconomic status (early } \\
\text { life)) }\end{array}$ & $0.94(0.54$ to 1.65$)$ & 0.84 \\
\hline $\begin{array}{l}\text { Model } 9 \\
\text { (classic+individual socioeconomic status (all)) }\end{array}$ & 1.12 (0.53 to 2.37$)$ & 0.76 \\
\hline $\begin{array}{l}\text { Model } 10 \\
\text { (classic+all) }\end{array}$ & $1.05(0.45$ to 2.44$)$ & 0.91 \\
\hline
\end{tabular}

Model 1: adjusted for age, sex, and scans present.

Model 2 (classic risk factors): adjusted for age, sex, scans present, triglycerides, low density lipoprotein cholesterol, high density lipoprotein cholesterol, systolic blood pressure, diastolic blood pressure, smoking, and history of hypertension.

Model 3 (classic+insulin resistance markers): as Model 2+waist circumference, glucose, Homeostasis Model of Assessment-Insulin Resistance (HOMA-IR), adiponectin, leptin, and history of diabetes.

Model 4 (classic+inflammatory): as Model $2+C$ reactive protein, interleukin 6 , and intercellular adhesion molecule 1.

Model 5 (classic+haemostasis): as Model 2+fibrinogen, D-dimer, and von Willebrand factor.

Model 6 (classic+physical activity): as Model 2+physical activity.

Model 7 (classic+all "emerging"+physical activity): as Model 2+ waist circumference, glucose, Homeostasis

Model of Assessment-Insulin Resistance, adiponectin, leptin, history of diabetes, $\mathrm{C}$ reactive protein, interleukin 6 , intercellular adhesion molecule 1, fibrinogen, D-dimer, von Willebrand factor, and physical activity.

Model 8 (classic+individual socioeconomic status (early life)): as Model 2+height, leg length, people per room at age 11 years, father's Registrar General social class, and total years of education.

Model 9 (classic+individual socioeconomic status (all)): as Model 8+participant's Registrar General social class and annual household income.

Model 10 (classic+all): as Model 2+waist circumference, glucose, Homeostasis Model of Assessment-Insulin Resistance, adiponectin, leptin, history of diabetes, $C$ reactive protein, interleukin 6 , intercellular adhesion molecule 1, fibrinogen, D-dimer, von Willebrand factor, physical activity, height, leg length, people per room at age 11 years, father's Registrar General social class, participant's Registrar General social class, annual household income, and total years of education.
$95 \%$ confidence interval 1.07 to $2.82 ; \mathrm{P}=0.026)$. In general terms, individuals from the most deprived areas had around a 1.5-fold to 2 -fold higher risk of plaque presence than those from least deprived areas.

In contrast to the effect on intima-media thickness, however, inclusion of individual level markers of early life socioeconomic status (height, leg length, people per room at age 11 years, father's Registrar General social class, and total years of education; model 8) abolished the difference in plaque presence between individuals from the most deprived areas and those from the least deprived areas (adjusted odds ratio for plaque presence $0.94,95 \%$ CI 0.54 to $1.65 ; \mathrm{P}=0.84)$. When all individual level markers of socioeconomic status (height, leg length, people per room at age 11 years, father's Registrar General social class, participant's Registrar General social class, annual income, and total years of education) were each added in turn to a model, none of the individual level markers of socioeconomic status on their own abolished the area level deprivation based difference in plaque presence (data not shown).

\section{DISCUSSION}

This study examined the prevalence of carotid atherosclerosis in participants at extremes of the socioeconomic gradient in Glasgow, a city whose inhabitants have well documented health issues associated with social deprivation. We found that carotid plaque score and intima-media thickness were significantly worse in participants from the bottom $5 \%$ of all areas classed by the Scottish Index of Multiple Deprivation than in individuals living in areas classified as being in the top 20\%. Although there were clear differences in biomarkers of chronic inflammation between the participants from the two groups, neither these factors nor classic risk factors satisfactorily explained the increased atherosclerosis burden in the lower socioeconomic status group. Adjusting for individual level markers of socioeconomic status eliminated the area level difference in plaque presence, although this adjustment did not reduce the area level difference in intima-media thickness.

A striking finding in this study is that a difference between the two groups in plaque score appeared at an earlier age than a difference in intima-media thickness, although the trends in intima-media thickness are as expected (rising with age; greater in males). The difference in intima-media thickness between participants from the least and most deprived areas did not reach statistical significance in women at any age tertile studied. This finding is not surprising given that the difference in men only reached statistical significance in the highest age tertile and the fact that atherosclerosis tends to develop around a decade later in women than in men.

In contrast to intima-media thickness, differences in plaque score were highly statistically significant, reaching significance in the two highest age tertiles in men and the highest age tertile in women. This observation 


\section{WHAT IS ALREADY KNOWN ON THIS TOPIC}

Coronary heart disease is more prevalent in areas of relative social deprivation than in socioeconomically advantaged areas

This health gap is not satisfactorily explained by currently recognised ("classic") cardiovascular risk factors

A number of novel ("emerging") risk factors have been identified that might contribute to deprivation based differences in cardiovascular disease

\section{WHAT THIS STUDY ADDS}

Indices of atherosclerosis (carotid intima-media thickness and plaque presence), as determined by ultrasound, are significantly higher in people from more deprived areas; plaque score being the more sensitive marker

Adjustment for classic cardiovascular risk factors and emerging risk factors associated with insulin resistance, inflammation, endothelial dysfunction, and haemostasis does not abolish the deprivation based difference in ultrasound markers of atherosclerosis

Adjustment for individual level markers of socioeconomic status as well as classic and emerging risk markers likewise does not abolish the difference in carotid intima-media thickness between men from the least deprived areas and those from the most deprived areas

suggests that plaque score measured in a standardised, objective, and blinded way could show differences between most deprived and least deprived individuals more accurately than intima-media thickness because plaque score may be more sensitive in detecting atherosclerosis.

On multivariate analysis, adjusting for classic risk factors reduced but did not abolish the deprivation based difference in plaque presence and intima-media thickness, strongly suggesting that classic risk factors do not fully explain the difference in ultrasound markers of atherosclerosis between participants from most and least deprived areas.

Inflammatory pathways are involved in atherosclerosis, ${ }^{41}$ and significant differences in inflammatory markers were noted between deprivation categories in this study and in other studies. ${ }^{42}$ Thus, the inclusion of markers of inflammation or endothelial dysfunction might have been expected to reduce or abolish the significant difference in plaque score. However, none of the measured markers of inflammation, insulin resistance, or haemostasis had a significant impact on the difference in plaque presence between the two deprivation groups, with area level deprivation remaining a significant predictor even once all classic and emerging risk factors were included in the model. These findings are consistent with those from the Women's Health Study, in which the inverse association between educational attainment and risk of cardiovascular events was not reduced by adjusting for $\mathrm{C}$ reactive protein, intercellular adhesion molecule 1 , fibrinogen, or homocysteine. ${ }^{43}$

Only by adjusting for individual level markers of socioeconomic status was the difference in plaque presence between participants from the least and most deprived areas abolished. Even this adjustment did not explain the deprivation based difference in intima-media thickness in males. Given that area level and individual level markers of socioeconomic status are likely to be highly correlated, it is clearly plausible that the abolition of the area level deprivation based difference in plaque presence on adjusting for individual level markers of socioeconomic status might be the result of overadjustment.

It would be of interest to know whether assessment of plaque volume would yield further useful information, ${ }^{44}$ but the technology allowing such assessment is not yet widely available.

\section{Strengths and limitations of study}

Several strengths of this study are worthy of comment. Participants were selected on the basis of area level deprivation category as classified by the Scottish Index of Multiple Deprivation, rather than the effects of socioeconomic status being examined post hoc. The setting of Glasgow, Scotland, is excellent for such a study because a wide range of deprivation and life expectancy can be found within the city. The complete dataset, with relatively few missing results, is also a strength of this study.

Limitations of this study include the fact that only individuals from the two extremes of area level social deprivation were included. Social deprivation exists as a continuum, and it could be argued that a full understanding of the effects of deprivation cannot be achieved by studying only individuals at the two extremes. We decided for practical purposes, and also to maximise the opportunity to identify differences between most and least deprived populations, that a study design looking at the two extremes of deprivation was appropriate.

Another concern of this study is the question of whether study participants differed from non-participants. In particular, it is possible that the "worried well" and the "healthy deprived" would preferentially volunteer for this study, thus minimising potential differences between least and most deprived communities. Our comparison of study participants with individuals in the anonymised data obtained from the General Practice Administration System for Scotland demonstrated differences between participants and non-participants. We found higher levels of prescriptions for statins, antihypertensives, and antidiabetic drugs in participants compared with non-participants, especially in the most deprived group, which implies that those who participated had a higher level of recognised morbidity than those who did not participate. In addition, such individuals were probably more concerned about their health or were more used to visiting their general practitioner.

A further concern could be raised regarding whether the findings from this study are generalisable to populations other than those living in the NHS Greater Glasgow area. Ongoing research by the Glasgow Centre for Population Health, however, suggests that current levels (and distributions) of socioeconomic deprivation in Glasgow are almost identical to those seen in Liverpool and in Manchester (Glasgow Centre for Population Health, unpublished data). Thus, the deprivation profile of Glasgow is not unique in the 
context of other post-industrial cities in the United Kingdom.

\section{Conclusions and policy implications}

This study demonstrates the great significance of area level socioeconomic deprivation as a predictor of atherosclerosis. Classic cardiovascular risk factors did not fully explain the difference in plaque presence between participants from the most deprived areas and those from the least deprived areas, suggesting that current public health messages directed at classic risk factors (diet, blood pressure, smoking) may not adequately address the continuing socioeconomic gradient in cardiovascular disease. The findings in this study add weight to the case for inclusion of social deprivation in cardiovascular risk assessment, as has been done in the ASSIGN (ASSessing cardiovascular risk using SIGN) scoring system. ${ }^{45}$

Although the deprivation based difference in atherosclerosis was not explained by the classic risk factors examined, neither was it explained by the range of emerging markers measured in this study. Health status is a reflection not only of features of the individual but also of wider social and economic influences, health and social services, early life experiences, and environmental factors. The analyses reported here focused on biological pathways that might explain the disparity (for example, insulin resistance, inflammation, and haemostasis). Further analyses focusing on the relative strengths of different pathways in explaining the health gap between the most and least deprived participants may help in unravelling the multifactorial nature of health inequalities.

We thank W Hanselaar and J Gort in the Department of Vascular Medicine and W Stok in the Department of Physiology, Academic Medical Centre, Amsterdam, The Netherlands, for advice relating to carotid ultrasound and for use of the eTrack software. We also thank Prof GD Lowe and Dr A Rumley in the Department of Vascular Medicine, University of Glasgow and colleagues in the Department of Vascular Biochemistry, University of Glasgow and the Department of Clinical Biochemistry, Glasgow Royal Infirmary, for analysis of blood samples. Thanks finally to staff in the Robertson Centre for Biostatistics for data input and statistical analysis, staff in the Glasgow Centre for Population Health for administrative support, staff in the general practices from whom the participants were drawn, and, above all, the participants.

Contributors: KAD analysed the carotid scans and wrote the original manuscript draft. KAD, IF, GDB, HB, JC, EdG, KM, PGS, CT, YNV, NS, and CJP contributed equally to the conception and design of the study, and had final approval of the version to be published. VB performed the statistical analysis. AM supervised the recruitment of participants and data collection, and performed the majority of the carotid ultrasound scans. CJP is guarantor

Funding: This study was funded by the Glasgow Centre for Population Health, a partnership between NHS Greater Glasgow and Clyde, Glasgow City Council, and the University of Glasgow and supported by the Scottish Government. All study data were held by the Robertson Centre for Biostatistics and remained blinded until after data lock after the end of data collection. Study data were then unblinded and analysed by the Robertson Centre for Biostatistics. Furthermore, the Glasgow Centre for Population Health had no competing interest (financial or otherwise) related to the findings of the study.

Competing interests: None declared.

Ethical approval: The study was reviewed and approved by the Glasgow Royal Infirmary Research Ethics Committee; all participants gave written informed consent.

Data sharing:No additional data available.
1 Wohl A. Endangered lives: public health in Victorian Britain. JM Dent, 1983.

2 Marmot M, Wilkinson R. Social determinants of health. 2nd ed.Oxford University Press, 2005.

3 Marmot M, Brunner E. Cohort profile: the Whitehall II study. Int J Epidemiol 2005;34:251-6.

4 Davey Smith G, Lynch J. Life course socioeconomic differentials in health. In: Ben-Shlomo Y, Kuh D, eds. A life course approach to chronic disease epidemiology. Oxford University Press, 2004.

5 Davey Smith G, Neaton J, Wentworth D, Stamler R, Stamler J. Socioeconomic differentials in mortality risk among men screened for the multiple risk factor intervention trial: I. White men. Am J Public Health 1996;8:486-96.

6 Lawlor D, Davey Smith G, Patel R, Ebrahim S. Life-course socioeconomic position, area deprivation, and coronary heart disease: findings from the British Women's Heart and Health Study. Am J Public Health 2005;95:91-7.

7 Kaplan GA, Keil JE. Socioeconomic factors and cardiovascular disease: a review of the literature. Circulation 1993;88:1973-98.

8 Batty GD, Der G, Macintyre S, Deary IJ. Does IQ explain socioeconomic inequalities in health? Evidence from a population based cohort study in the west of Scotland. BMJ 2006;332:580-4.

9 National Institutes of Health. Third report of the National Cholesterol Education Program (NCEP) expert panel on detection, evaluation, and treatment of high blood cholesterol in adults (adult treatment panel III). 2002. www.nhlbi.nih.gov/guidelines/cholesterol/atp3full. pdf.

10 Shewry M, Smith W, Woodward M, Tunstall-Pedoe H. Variation in coronary risk factors by social status: results from the Scottish Heart Health Study. Br J Gen Pract 1992;42:406-10.

11 Tunstall-Pedoe $\mathrm{H}$, Woodward M, Tavendale R, A'Brook R, McCluskey M. Comparison of the prediction by 27 different factors of coronary heart disease and death in men and women of the Scottish heart health study: cohort study. BMJ 1997;315:722-9.

12 van Rossum CTM, Shipley MJ, van de Mheen H, Grobbee DE, Marmot MG. Employment grade differences in cause specific mortality. A 25 year follow up of civil servants from the first Whitehall study. J Epidemiol Community Health 2000;54:178-84.

13 Yudkin JS, Stehouwer CD, Emeis JJ, Coppack SW. C-reactive protein in healthy subjects: associations with obesity, insulin resistance, and endothelial dysfunction: a potential role for cytokines originating from adipose tissue? Arterioscler Thromb Vasc Biol 1999;19:972-8.

14 Lorenz MW, Markus HS, Bots ML, Rosvall M, Sitzer M. Prediction of clinical cardiovascular events with carotid intima-media thickness: a systematic review and meta-analysis. Circulation 2007;115:459-67.

15 Touboul PJ, Hennerici MG, Meairs S, Adams H, Amarenco P, Bornstein $\mathrm{N}$, et al. for the Mannheim carotid intima-media thickness consensus (2004-2006). An update on behalf of the advisory board of the 3rd and 4th Watching the Risk Symposium, 13th and 15th European Stroke Conferences, Mannheim, Germany, 2004, and Brussels, Belgium, 2006. Cerebrovasc Dis 2007;23:75-80.

16 Van der Meer IM, Bots ML, Hofman A, del Sol Al, van der Kuip DA, Witteman JC. Predictive value of noninvasive measures of atherosclerosis for incident myocardial infarction: the Rotterdam Study. Circulation 2004;109:1089-94.

17 Johnsen SH, Mathiesen EB, Joakimsen O, Stensland E, Wilsgaard T, Lochen ML, et al. Carotid atherosclerosis is a stronger predictor of myocardial infarction in women than in men. A 6-year follow-up study of 6226 persons: the Troms $\varnothing$ Study. Stroke 2007;38:2872-80.

18 Simon A, Chironi G, Levenson J. Comparative performance of subclinical atherosclerosis tests in predicting coronary heart disease in asymptomatic individuals. Eur Heart J 2007;28:2967-71.

19 Hollander M, Hak AE, Koudstaal PJ, Bots ML, Grobbee DE, Hofman A, et al. Comparison between measures of atherosclerosis and risk of stroke: the Rotterdam Study. Stroke 2003;34:2367-72.

20 Belcaro G, Nicolaides AN, Ramaswami G, Cesarone MR, De Sanctis M, Incandela L, et al. Carotid and femoral ultrasound morphology screening and cardiovascular events in low risk subjects: a 10-year follow-up study (the CAFES-CAVE study(1)) Atherosclerosis 2001;156:379-87.

21 Salonen JT, Salonen R. Ultrasonographically assessed carotid morphology and the risk of coronary heart disease. Arterioscler Thromb 1991:11:1245-9.

22 Stein JH, Korcarz CE, Hurst RT, Lonn E, Kendall CB, Mohler ER, et al. Use of carotid ultrasound to identify subclinical vascular disease and evaluate cardiovascular disease risk: a consensus statement from the American Society of Echocardiography Carotid Intima-Media Thickness Task Force. Endorsed by the Society for Vascular Medicine. J Am Soc Echocardiogr 2008;21:93-111.

23 Diez-Roux AV, Nieto FJ, Tyroler HA, Crum LD, Szklo M. Social inequalities and atherosclerosis. The atherosclerosis risk in communities study. Am J Epidemiol 1995;141:960-72.

24 Ranjit N, Diez-Roux AV, Chambless L, Jacobs DR Jr, Nieto FJ, Szklo M. Socioeconomic differences in progression of carotid intima-media 
thickness in the atherosclerosis risk in communities study. Arterioscler Thromb Vasc Biol 2006;26:411-6.

25 Lynch J, Kaplan GA, Salonen R, Cohen RD, Salonen JT. Socioeconomic status and carotid atherosclerosis. Circulation 1995;92:1786-92.

26 Lynch J, Kaplan GA, Salonen R, Salonen JT. Socioeconomic status and progression of carotid atherosclerosis. Prospective evidence from the Kuopio Ischemic Heart Disease Risk Factor Study. Arterioscler Thromb Vasc Biol 1997;17:513-9.

27 Lamont D, Parker L, White M, Unwin N, Bennett SM, Cohen M, et al. Risk of cardiovascular disease measured by carotid intima-media thickness at age 49-51: lifecourse study. BMJ 2000;320:273-8.

28 Kivimaki M, Smith GD, Juonala M, Ferrie JE, Keltikangas-Jarvinen L, Elovainio $M$, et al. Socioeconomic position in childhood and adult cardiovascular risk factors, vascular structure, and function: cardiovascular risk in young Finns study. Heart 2006;92:474-80.

29 Ebrahim S, Papacosta O, Whincup P, Wannamethee G, Walker M, Nicolaides AN, et al. Carotid plaque, intima media thickness, cardiovascular risk factors, and prevalent cardiovascular disease in men and women: the British Regional Heart Study. Stroke 1999;30:841-50.

30 Rosvall M, Engstrom G, Hedblad B, Janzon L, Berglund G. Area social characteristics and carotid atherosclerosis. Eur J Public Health 2007;17:333-9.

31 Petersen KL, Bleil ME, McCaffery J, Mackey RH, Sutton-Tyrrell K, Muldoon MF, et al. Community socioeconomic status is associated with carotid artery atherosclerosis in untreated, hypertensive men. Am J Hypertens 2006;19:560-6.

32 Hanlon P, Walsh D, Whyte B. Let Glasgow flourish: a comprehensive report on health and its determinants in Glasgow and west central Scotland. Glasgow Centre for Population Health, 2006.

33 Velupillai YN, Packard CJ, Batty GD, Bezlyak V, Burns H, Cavanagh J, et al. Psychological, social and biological determinants of ill health (pSoBid): study protocol of a population-based study. BMC Public Health 2008;8:126.

34 Scottish Government. Scottish index of multiple deprivation. 2004. www.scotland.gov.uk/Topics/Statistics/SIMD/Overview.
35 National Heart and Lung Institute. Manual of laboratory operations: lipid research clinics program. US Department of Health, Education, and Welfare, 1975.

36 McConway MG, Johnson D, Kelly A, Griffin D, Smith J, Wallace AM. Differences in circulating concentrations of total, free and bound leptin relate to gender and body composition in adult humans. Ann Clin Biochem 2000;37:717-23.

37 Khaw K-T, Jakes R, Bingham S, Welch A, Luben R, Day N, et al. Work and leisure time physical activity assessed using a simple, pragmatic, validated questionnaire and incident cardiovascular disease and all-cause mortality in men and women: the European prospective investigation into cancer in Norfolk prospective population study. Int J Epidemiol 2006;35:1034-43.

38 Bots ML, Hoes AW, Koudstaal PJ, Hofman A, Grobbee DE. Common carotid intima-media thickness and risk of stroke and myocardial infarction: the Rotterdam Study. Circulation 1997;96:1432-7.

39 Lawlor DA, Ebrahim S, Whincup P, Sterne J, Papacosta O, Wannamethee G, et al. Sex differences in body fat distribution and carotid intima media thickness: cross sectional survey using data from the British regional heart study. J Epidemiol Community Health 2004; 58:700-4.

40 NHS Scotland. General practice administration system for Scotland. 2005. www.gpass.scot.nhs.uk.

41 Libby P, Ridker PM, Maseri A. Inflammation and atherosclerosis. Circulation 2002;105:1135-43.

42 O'Reilly DSJ, Upton MN, Caslake MJ, Robertson M, Norrie J, $\mathrm{McC}$ Connachie $\mathrm{A}$, et al. Plasma $\mathrm{C}$ reactive protein concentration indicates a direct relation between systemic inflammation and social deprivation. Heart 2006;92:533-5.

43 Albert MA, Glynn RJ, Buring J, Ridker PM. Impact of traditional and novel risk factors on the relationship between socioeconomic status and incident cardiovascular events. Circulation 2006;114:2619-26.

44 Fenster A, Blake C, Gyacskov I, Landry A, Spence JD. 3D ultrasound analysis of carotid plaque volume and surface morphology. Ultrasonics 2006;44(Suppl 1):e153-7.

45 NHS Scotland. The ASSIGN score. 2008. www.assign-score.com.

Accepted: 2 June 2009 